NASA/TM-2006-213885

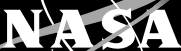

A Compact, Broadband Antenna for Planetary Surface-to-Surface Wireless Communications

Philip Barr, Afroz Zaman, and Félix Miranda

Glenn Research Center, Cleveland, Ohio 


\section{NASA STI Program . . . in Profile}

Since its founding, NASA has been dedicated to the advancement of aeronautics and space science. The NASA Scientific and Technical Information (STI) program plays a key part in helping NASA maintain this important role.

The NASA STI Program operates under the auspices of the Agency Chief Information Officer. It collects, organizes, provides for archiving, and disseminates NASA's STI. The NASA STI program provides access to the NASA Aeronautics and Space Database and its public interface, the NASA Technical Reports Server, thus providing one of the largest collections of aeronautical and space science STI in the world. Results are published in both non-NASA channels and by NASA in the NASA STI Report Series, which includes the following report types:

- TECHNICAL PUBLICATION. Reports of completed research or a major significant phase of research that present the results of NASA programs and include extensive data or theoretical analysis. Includes compilations of significant scientific and technical data and information deemed to be of continuing reference value. NASA counterpart of peer-reviewed formal professional papers but has less stringent limitations on manuscript length and extent of graphic presentations.

- TECHNICAL MEMORANDUM. Scientific and technical findings that are preliminary or of specialized interest, e.g., quick release reports, working papers, and bibliographies that contain minimal annotation. Does not contain extensive analysis.

- CONTRACTOR REPORT. Scientific and technical findings by NASA-sponsored contractors and grantees.
- CONFERENCE PUBLICATION. Collected papers from scientific and technical conferences, symposia, seminars, or other meetings sponsored or cosponsored by NASA.

- SPECIAL PUBLICATION. Scientific, technical, or historical information from NASA programs, projects, and missions, often concerned with subjects having substantial public interest.

- TECHNICAL TRANSLATION. Englishlanguage translations of foreign scientific and technical material pertinent to NASA's mission.

Specialized services also include creating custom thesauri, building customized databases, organizing and publishing research results.

For more information about the NASA STI program, see the following:

- Access the NASA STI program home page at http://www.sti.nasa.gov

- E-mail your question via the Internet to help@sti.nasa.gov

- Fax your question to the NASA STI Help Desk at 301-621-0134

- Telephone the NASA STI Help Desk at 301-621-0390

- Write to:

NASA STI Help Desk

NASA Center for AeroSpace Information 7121 Standard Drive Hanover, MD 21076-1320 
NASA/TM-2006-213885

(245)

A Compact, Broadband Antenna for Planetary Surface-to-Surface Wireless Communications

Philip Barr, Afroz Zaman, and Félix Miranda

Glenn Research Center, Cleveland, Ohio

National Aeronautics and

Space Administration

Glenn Research Center

Cleveland, Ohio 44135 


\section{Acknowledgments}

The authors would like to acknowledge Kevin Lambert of Analex Corporation and Richard Lee of the NASA Glenn Research Center for their contributions to this project.

Trade names and trademarks are used in this report for identification only. Their usage does not constitute an official endorsement, either expressed or implied, by the National Aeronautics and Space Administration.

Level of Review: This material has been technically reviewed by technical management.

Available from

NASA Center for Aerospace Information 7121 Standard Drive

Hanover, MD 21076-1320
National Technical Information Service 5285 Port Royal Road Springfield, VA 22161 


\title{
A Compact, Broadband Antenna for Planetary Surface-to-Surface Wireless Communications
}

\author{
Philip Barr, Afroz Zaman, and Félix Miranda \\ National Aeronautics and Space Administration \\ Glenn Research Center \\ Cleveland, Ohio 44135
}

\begin{abstract}
The Compact Microstrip Monopole Antenna (CMMA) is a novel antenna design that combines a microstrip patch antenna with a three-dimensional structure to attain a highly directive, broadband, compact antenna. A Tri-Lobed Patch (TLP) was designed to minimize the patch's area while reducing the antenna's operating frequency. A Grounding Wall $(\mathrm{GW})$ connects the patch to the ground plane and a Vertical Enclosure Wall (VEW) extends up away from portions of the patch's perimeter. This VEW supplies the antenna with a higher directivity in the radial direction as well as reduces the operating frequency. The CMMA was designed to operate at $2.23 \mathrm{GHz}$, but experimental results have shown this antenna resonates at $2.05 \mathrm{GHz}$ which is on the order of approximately $\lambda_{\mathrm{o}} / 11.6$ with respect to the antenna's largest dimension, with a directivity and bandwidth of $6.0 \mathrm{dBi}$, and $130 \mathrm{MHz}(6.3$ percent), respectively. This miniature, radially emitting antenna makes the CMMA attractive for planetary-based surface-to-surface communications.
\end{abstract}

\section{Introduction}

NASA's vision for space exploration calls for extending the human presence throughout the solar system through both human and robotic missions (ref. 1). This vision will be realized with a return to the moon by 2020 in preparation for future human missions to Mars and beyond. As NASA begins exploring these destinations a flexible, reliable, and cost-effective wireless communications network will be needed. This wireless communications network will be required to support various types of communications including voice, data, imaging, and video to and from an assortment of mobile and non-mobile nodes. To achieve these goals a concerted research effort into miniature antenna technologies is ongoing at the NASA Glenn Research Center (GRC). The Compact Microstrip Monopole Antenna (CMMA) presented in this paper is one of the outcomes of this ongoing effort.

The CMMA radiates like a miniature monopole antenna with a height of less than $\lambda_{\mathrm{o}} / 11.6$, where $\lambda_{\mathrm{o}}$ is the wavelength of the electromagnetic signal in free space. This small size was achieved by attaching a Grounding Wall (GW) along a small section of the perimeter of a Tri-Lobed Patch (TLP) (ref. 2). Efforts by other groups (e.g., the Dime Antenna (refs. 3 and 4)) have shown that the operating frequency of these grounded patches was determined by the length of the ungrounded perimeter, plus the length of the GW. The TLP achieves a larger perimeter while maintaining a smaller area to reduce the operating frequency while minimizing size. Although this approach significantly reduces the antenna's operating frequency, the directivity is greatly diminished. To address this problem a Vertical Enclosure Wall (VEW) was attached to portions of the TLP's perimeter to increase the antenna's directivity and further reduce the antenna's operating frequency, in our case by as much as $500 \mathrm{MHz}$.

\section{Compact Microstrip Monopole Antenna (CMMA) Design and Fabrication}

The CMMA was designed and simulated using Zealand's IE3D electromagnetic simulator to radiate at $2.23 \mathrm{GHz}$, a frequency within the band being considered for Lunar and Martian surface-to-surface communications (refs. 5 and 6). The TLP was designed on a $1.57 \mathrm{~mm}$ thick substrate with a relative dielectric constant of $\varepsilon_{\mathrm{r}}=2.2$ over a ground plane. A series of six connected circles located at the corners 
of an equilateral hexagon defines the layout of this patch. The diameter of each circle is $4.60 \mathrm{~mm}$ which is also equal to one side of the equilateral hexagon. Figure 1 illustrates the design technique used for the TLP. In figure 2 the locations of the GW and the VEW are depicted. A GW approximately $1.20 \mathrm{~mm}$ wide was attached from the perimeter of the patch to the ground plane spanning the $1.57 \mathrm{~mm}$ thickness of the substrate. A VEW of $11.0 \mathrm{~mm}$ in height and $31.2 \mathrm{~mm}$ in length was attached to the perimeter of the TLP and distributed evenly around the 2 lobes which are directly opposite the lobe containing the GW.
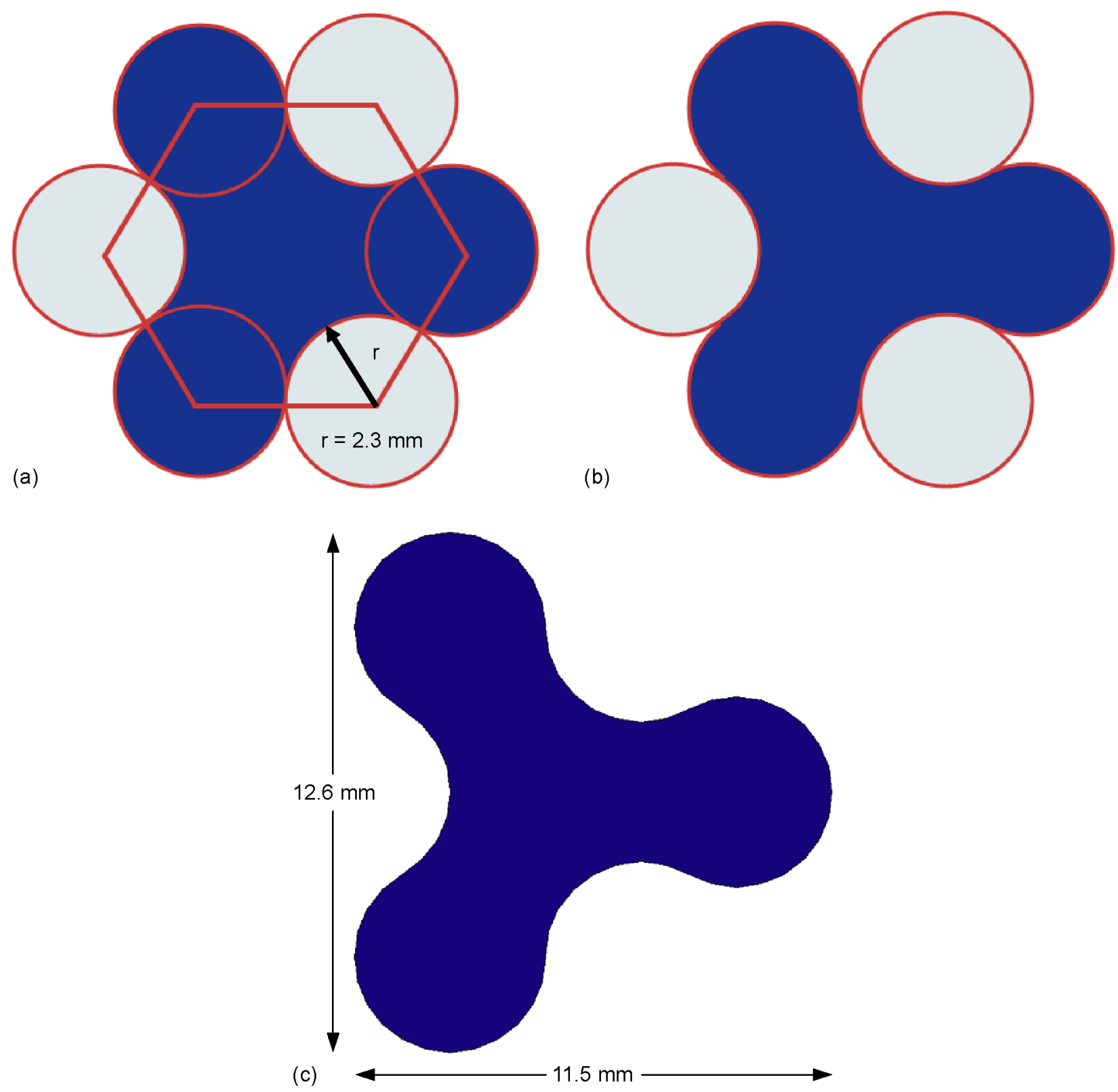

Figure 1.-The design technique used for laying out the tri-lobed patch (TLP) in the CMMA. (a) A depiction of the equilateral hexagon used to determine the location of the six uniform circles with a radius of $2.3 \mathrm{~mm}$. (b) The darker region depicts the area used to define the TLP from part a. (c) The TLP design used in the CMMA. This patch was fabricated on $1.57 \mathrm{~mm}$ Duroid ${ }^{\circledR} 5880$ with a relative dielectric constant of $\varepsilon_{\mathrm{r}}=2.2$. 


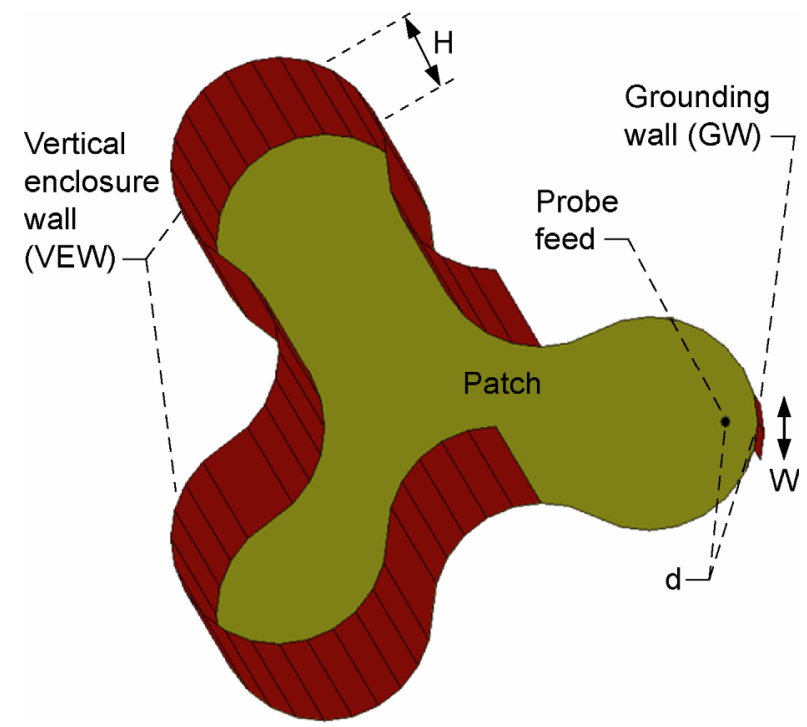

Figure 2.-A 3-dimensional diagram of the CMMA. The grounding wall (GW) on the right connecting the tri-lobed patch (TLP) to the ground plane is $1.57 \mathrm{~mm}$ in height and $W=1.20 \mathrm{~mm}$ wide. A coaxial probe is fed from the bottom through the substrate $\mathrm{d}=0.75 \mathrm{~mm}$ from the GW . The vertical enclosure wall (VEW) on the left extends $\mathrm{H}=11.0 \mathrm{~mm}$ up away from the TLP's perimeter while wrapping $31.2 \mathrm{~mm}$ of the perimeter opposite of the GW.

The prototype shown in figure 3 was fabricated at NASA GRC on $1.57 \mathrm{~mm}$ Duroid $^{\circledR} 5880$ (Rogers Corporation, Chandler, AZ) with a relative dielectric constant of $\varepsilon_{\mathrm{r}}=2.2$. The copper surface of the Duroid $^{\circledR} 5880$ was etched to pattern the TLP used in the CMMA. The GW and VEW were fabricated using copper tape. The adhesive from the copper tape was removed using a ketone-based solvent. The $50 \mu \mathrm{m}$ thick walls were shaped appropriately and attached to the patch using Ablebond, a conductive epoxy. A coaxial probe was inserted through the Duroid ${ }^{\circledR} 5880$ to feed an RF signal from below the antenna through the substrate to the TLP. This probe was attached $0.75 \mathrm{~mm}$ from the GW. The outer conductor of the coaxial probe was removed near the ground plane to prevent electrical shorting.

\section{Experimental Testing and Results}

The CMMA was measured using an HP 8510C network analyzer which showed an optimal $\mathrm{S}_{11}$ performance at $2.05 \mathrm{GHz}$. The measured difference in this operating frequency from simulation could be a result of fabrication constraints. The relative dielectric constant of the epoxy, which is nominally 4, may have been a factor contributing to the lowering of the operating frequency. Simulations that included this epoxy layer have shown a reduction in the operating frequency to what was observed in experiments. The $10 \mathrm{~dB}$ bandwidth of the fabricated antenna was approximately $130 \mathrm{MHz}$ (6.3 percent) which was larger than the simulated one of $50 \mathrm{MHz}$. Figure 4 compares the measured return loss of the CMMA with simulation. The broadening of the resonance is a result of the non-optimal matching and coupling losses between the RF probe feed and the antenna. 


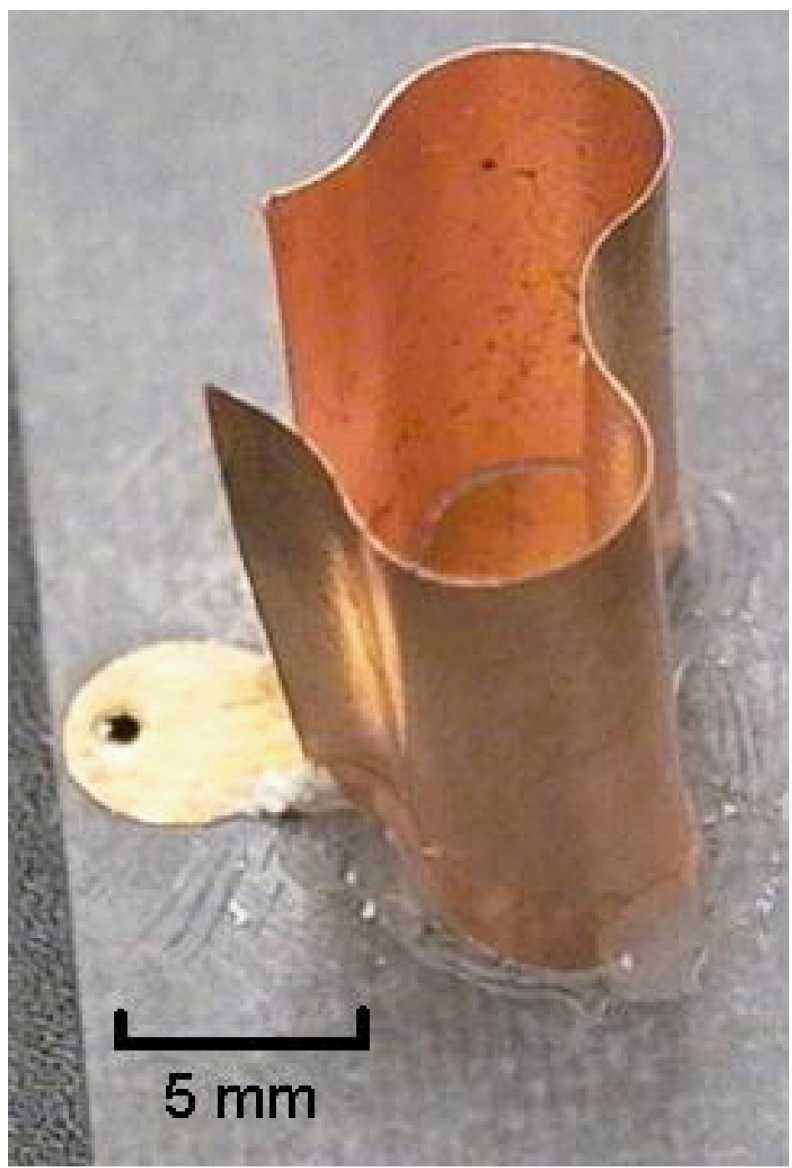

Figure 3.-The CMMA prototype fabricated at NASA GRC. The picture shows the vertical enclosure wall (VEW) on the right with the hole for the RF probe at the base of the CMMA on the left. 


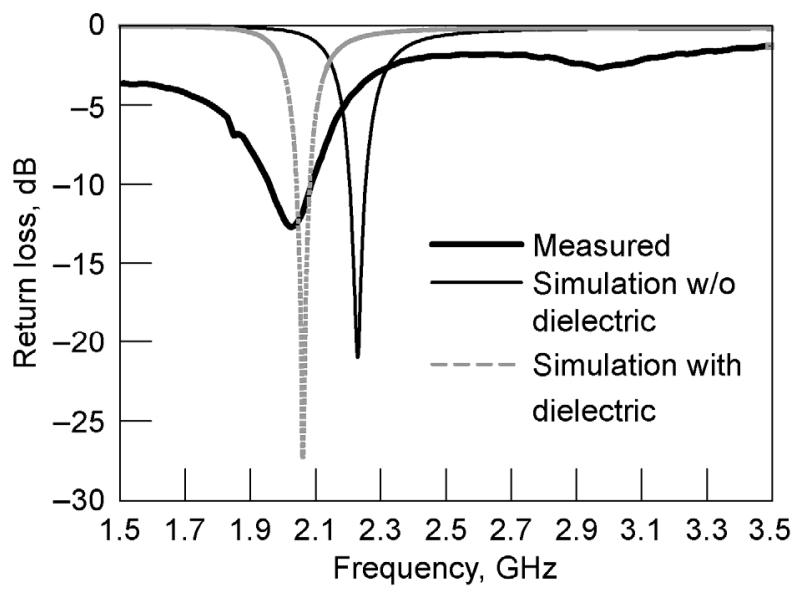

Figure 4.-The measured and simulated return losses for the CMMA. The operating frequency was measured at $2.05 \mathrm{GHz}$ with a $130 \mathrm{MHz}$ bandwidth (measured). The antenna was designed to operate at $2.23 \mathrm{GHz}$ with a bandwidth of $50 \mathrm{MHz}$ (simulation w/o dielectric). Also shown is the simulated data for the return loss of the CMMA taking into account the effects of the epoxy $\left(\varepsilon_{r} \sim 4\right)$ used to attach the VEW to the TLP (simulation with dielectric).

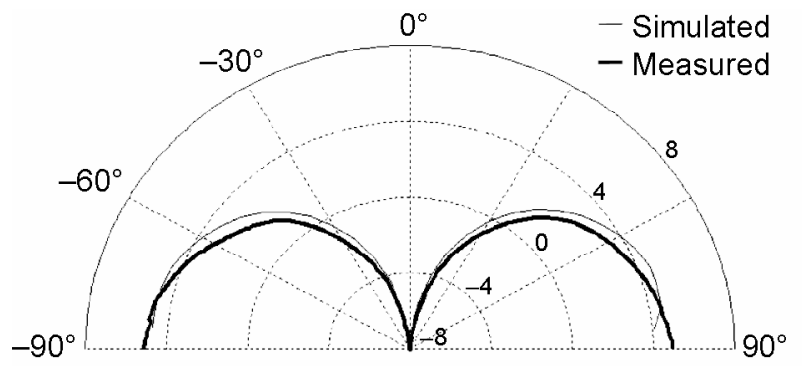

(a)

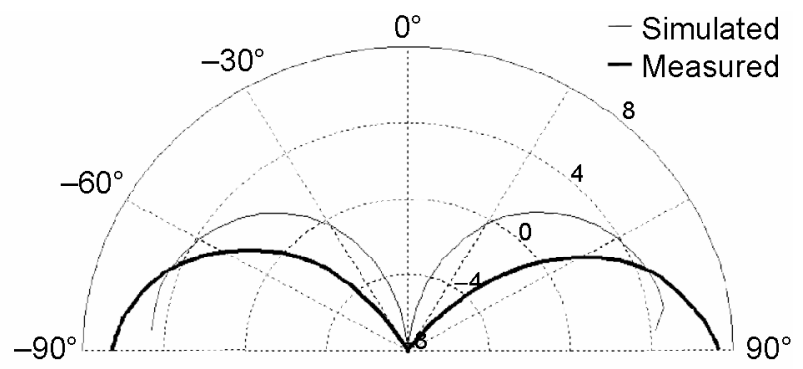

(b)

Figure 5.-Plots comparing the directivity of the measured and simulated radial radiation patterns of the CMMA at $2.05 \mathrm{GHz}$. (a) E-plane radiation pattern. (b) H-plane radiation pattern.

Experimental measurements of the CMMA's radiation patterns were performed in the Cylindrical Near Field Antenna Range at NASA GRC (ref. 7). The measured radiation patterns for the E-plane and $\mathrm{H}$-plane are shown in figure 5. The radial radiation characteristic of the CMMA indicates that the dominant radiation mechanism of the antenna is the surface current flowing on the VEW. This current is fed at the base of the wall and is distributed in a manner determined by the TLP. Note that this distribution is a function of frequency and hence it is the TLP that controls the frequency behavior of the antenna. The current flows vertically and must terminate at the top edge of the wall resulting in the radiated field. These currents can be viewed in the current distribution plot shown in figure 6 . The directivity of the CMMA prototype was calculated from the radiation pattern to be approximately $6.0 \mathrm{dBi}$ which is comparable to the simulated directivity of $5.0 \mathrm{dBi}$ and the quarter-wave monopole of $5.16 \mathrm{dBi}$ (ref. 8). 

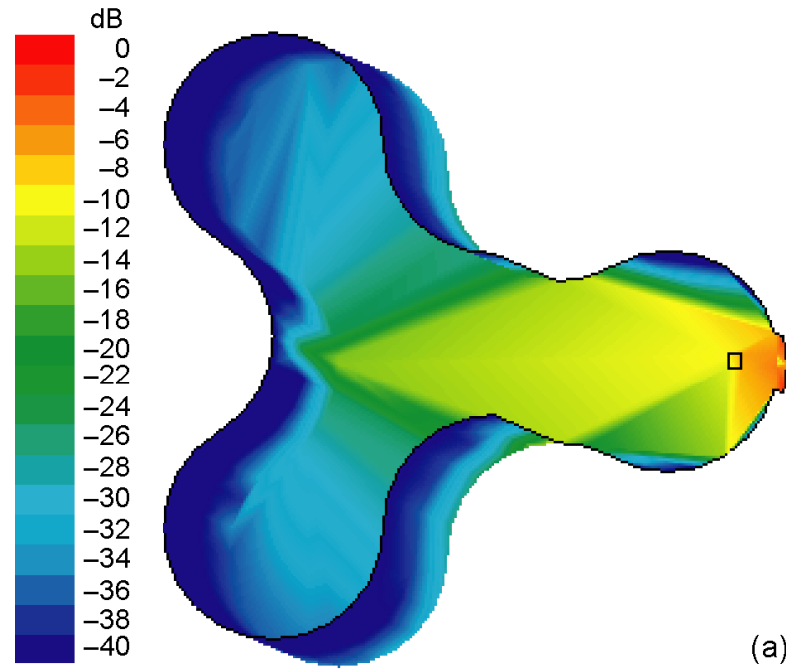

(a)

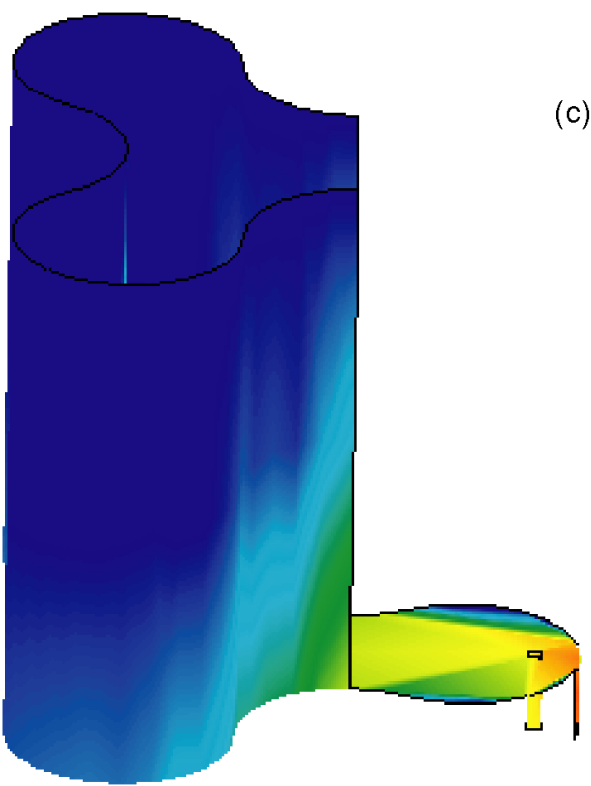

(c)
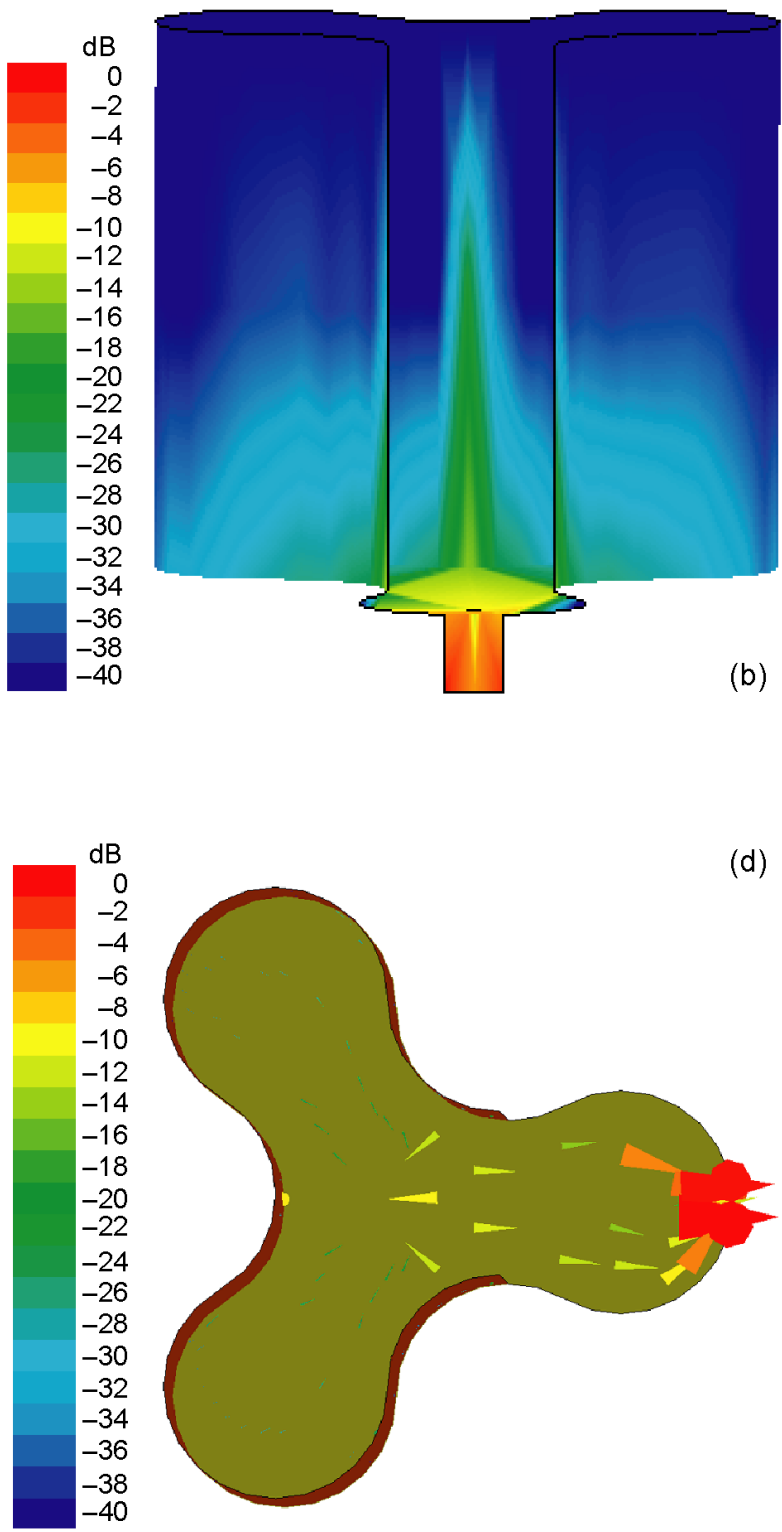

Figure 6.-The average current distribution through the CMMA. (a) Top view of the average current distribution (magnitude) through the TLP. (b) The average current distribution (magnitude) through the VEW as seen along the line of sight of the plane containing the probe feed and parallel to the TLP. (c) The average current distribution through the VEW looking at it from the side. (d) Top view of the vector distribution of current through the TLP.

\section{Conclusion}

With the CMMA's unique combination of a VEW and a microstrip patch, this miniature antenna retains its high directivity and large bandwidth properties as compared to typical miniature antennas which trade these properties to achieve their small sizes. Measured results have shown that the CMMA is capable of operating at less than $\lambda_{\mathrm{o}} / 11.6$ with no trade off in its directivity. The measured bandwidth and directivity for this antenna were $130 \mathrm{MHz}$ and $6.0 \mathrm{dBi}$, respectively. The CMMA has the potential for many applications where monopole antennas are typically used. Many mobile components in NASA's future missions such as sensors, rovers, robots, etc., will require radially directed antennas since the 
antenna's orientation and position cannot be predicted. The CMMA's small size makes it more suitable for integration than other larger monopole antennas. Future work for this antenna includes an investigation into a linear array of the CMMA elements to produce a highly directive radially radiating antenna.

\section{References}

1. National Aeronautics and Space Administration, The new age of exploration. NASA's direction for 2005 and beyond, July 15, 2005, <http://www.nasa.gov/pdf/107490main_FY06_Direction.pdf>

2. R. Waterhouse, Small microstrip patch antenna, IEE Electronics Letters, vol. 31, (1995), 604-605.

3. B.A. Cetiner, L. Jofre, F. Flaviis, N. Alexopoulos, and G. P. Li, A miniature broadband antenna for portable communications terminals, IEEE Antennas and Propagation Society International Symposium, vol. 4, (2001), 108-111.

4. B.A. Cetiner, L. Jofre, F. Flaviis, Reconfigurable miniature multielement antenna for wireless networking, IEEE Radio and Wireless Conference, (2001), 203-206.

5. D.L. Brandel, Spectrum recommendations for lunar relay and lunar proximity links, Presentation to NASA Architecture Sub-Group for Spectrum on June 24, 2004.

6. Space Frequency Coordination Group, Frequency assignment guidelines for communications in the mars region, July 15, 2005, <http://www.sfcgonline.org/handbook/rec/rec22-1r1.doc >

7. K. Lambert, G. Anzic, R. Zakrajsek, and A. Zaman, Overview of antenna measurement facilities at the NASA Glenn Research Center, Proceedings of the Antenna Measurement Techniques Association $24^{\text {th }}$ Annual Meeting \& Symposium, (2002), 549-554. Also found as NASA/TM-2002-211883, October 2002.

8. W.L. Stutzman, G.A. Thiele, Antenna theory and design, Edition 2, John Wiley \& Sons, Inc., (1998), 68. 
Public reporting burden for this collection of information is estimated to average 1 hour per response, including the time for reviewing instructions, searching existing data sources, gathering and maintaining the data needed, and completing and reviewing the collection of information. Send comments regarding this burden estimate or any other aspect of this collection of information, including suggestions for reducing this burden, to Washington Headquarters Services, Directorate for Information Operations and Reports, 1215 Jefferson Davis Highway, Suite 1204, Arlington, VA 22202-4302, and to the Office of Management and Budget, Paperwork Reduction Project (0704-0188), Washington, DC 20503.

\begin{tabular}{|l|l|l}
\hline 1. AGENCY USE ONLY (Leave blank) & $\begin{array}{c}\text { 2. REPORT DATE } \\
\text { November } 2006\end{array}$ & $\begin{array}{r}\text { 3. REPORT TYPE AND DATES COVERED } \\
\text { Technical Memorandum }\end{array}$
\end{tabular}

4. TITLE AND SUBTITLE 5. FUNDING NUMBERS

A Compact, Broadband Antenna for Planetary Surface-to-Surface Wireless

Communications

6. AUTHOR(S)

Philip Barr, Afroz Zaman, and Félix Miranda

WBS-22-612-30-81-04

National Aeronautics and Space Administration

John H. Glenn Research Center at Lewis Field

Cleveland, Ohio 44135-3191

8. PERFORMING ORGANIZATION

REPORT NUMBER

E-15256

9. SPONSORING/MONITORING AGENCY NAME(S) AND ADDRESS(ES)

10. SPONSORING/MONITORING

AGENCY REPORT NUMBER

National Aeronautics and Space Administration

Washington, DC 20546-0001

NASA TM-2006-213885

11. SUPPLEMENTARY NOTES

Responsible person, Philip Barr, organization code RCA, 216-433-6718.

12a. DISTRIBUTION/AVAILABILITY STATEMENT

12b. DISTRIBUTION CODE

Unclassified - Unlimited

Subject Categories: 88 and 91

Available electronically at http://gltrs.grc.nasa.gov

This publication is available from the NASA Center for AeroSpace Information, 301-621-0390.

13. ABSTRACT (Maximum 200 words)

The Compact Microstrip Monopole Antenna (CMMA) is a novel antenna design that combines a microstrip patch antenna with a three-dimensional structure to attain a highly directive, broadband, compact antenna. A Tri-Lobed Patch (TLP) was designed to minimize the patch's area while reducing the antenna's operating frequency. A Grounding Wall (GW) connects the patch to the ground plane and a Vertical Enclosure Wall (VEW) extends up away from portions of the patch's perimeter. This VEW supplies the antenna with a higher directivity in the radial direction as well as reduces the operating frequency. The CMMA was designed to operate at $2.23 \mathrm{GHz}$, but experimental results have shown this antenna resonates at $2.05 \mathrm{GHz}$ which is on the order of approximately $\lambda_{\mathrm{o}} / 11.6$ with respect to the antenna's largest dimension, with a directivity and bandwidth of $6.0 \mathrm{dBi}$, and $130 \mathrm{MHz}$ (6.3 percent), respectively. This miniature, radially emitting antenna makes the CMMA attractive for planetary-based surface-to-surface communications.

\section{SUBJECT TERMS} 15. NUMBER OF PAGES

Broadband antenna; Wireless communications; Compact microstrip monopole antenna; S-band; Surface-to-surface communications; Miniature antenna

\begin{tabular}{|c|c|c|}
\hline $\begin{array}{c}\text { 17. SECURITY CLASSIFICATION } \\
\text { OF REPORT } \\
\text { Unclassified }\end{array}$ & $\begin{array}{c}\text { 18. SECURITY CLASSIFICATION } \\
\text { OF THIS PAGE } \\
\text { Unclassified }\end{array}$ & $\begin{array}{c}\text { 19. SECURITY CLASSIFICATION } \\
\text { OF ABSTRACT } \\
\text { Unclassified }\end{array}$ \\
\hline
\end{tabular}



